\title{
Rotational Angle Measurement of Bridge Support Using Image Processing Techniques
}

\author{
Young-Soo Park, ${ }^{1}$ John Arbie Agbayani, ${ }^{1}$ Jong-Han Lee, ${ }^{2}$ and Jong-Jae Lee ${ }^{1}$ \\ ${ }^{1}$ Department of Civil and Environmental Engineering, Sejong University, 209 Neungdong-ro, Gwangjin-gu, \\ Seoul 143-747, Republic of Korea \\ ${ }^{2}$ Department of Civil Engineering, Daegu University, 201 Daegudae-ro, Gyeongsan-si, Gyeongsangbuk-do 712-714, Republic of Korea
}

Correspondence should be addressed to Jong-Jae Lee; jongjae@sejong.ac.kr

Received 11 August 2015; Accepted 3 November 2015

Academic Editor: Stefania Campopiano

Copyright (C) 2016 Young-Soo Park et al. This is an open access article distributed under the Creative Commons Attribution License, which permits unrestricted use, distribution, and reproduction in any medium, provided the original work is properly cited.

\begin{abstract}
Measuring a very small rotational angle accurately and dynamically is indeed a challenging issue, especially in the case of bridge support. Also, existing inclinometers do not have sufficient resolution and accuracy to measure a bridge's rotational angle. In this study, a new measurement system was developed to provide a practical means for measuring dynamic rotational angle of a bridge support. It features high resolution and accuracy compared with the available systems on the market. By the combinational use of a laser pointer and a vision-based displacement measurement system, the measurement accuracy was significantly increased. The accuracy and applicability were investigated through laboratory tests. From the laboratory tests, it has been found that the developed system can be applicable to bridge support with very small rotational angle. The effectiveness of the developed system was verified through field tests on real bridges. From the full-scale implementation on two PSC girder bridges, it is observed that the proposed system can measure the rotational angle with a high accuracy and reliability.
\end{abstract}

\section{Introduction}

It is a fact that bridges get deteriorated over time. As such, condition assessment of these structures has been a very important issue in maintenance work [1]. Evaluating a bridge's condition requires measuring a variety of physical quantities including bridge responses. Diverse sensors and techniques have been utilized to provide information on bridge performance. Bridge responses that are most often measured are displacement and strain [2-6]. Inclinometers are installed at pylons of cable bridges. Accelerometers are used to measure vibration of cables or a bridge deck [7]. Recently, smart sensors such as optical fiber sensors, optic sensors, and wireless sensors have been widely used to measure the above-mentioned bridge responses in a more accurate and effective manner [8-10].

Bridge supports are small integral parts of the entire bridge structure serving several key roles such as connecting bridge parts, allowing movements, and transferring forces.
Therefore, bridge supports could result in a serious problem to the whole system if not properly understood and maintained. Condition assessment of bridge supports is mainly carried out by visual inspection [11, 12]. Long-term monitoring of bridge supports has been carried out for a cable-stayed bridge to correlate the movement of bridge bearings with temperature changes [13]. Still, it is very difficult to obtain physical quantities from the supports, especially rotational angle. For example, the expected maximum rotational angle of a common bridge with a span length of $30 \mathrm{~m}$ will be around 0.01 degrees. Measuring a very small rotational angle accurately and dynamically is indeed a challenging issue.

Table 1 shows several examples of commercially available inclinometers. The best one has a resolution up to 0.0001 degrees and 0.003 degrees in accuracy. Still, existing inclinometers do not have sufficient resolution and accuracy to measure a bridge's rotational angle less than 0.003 degrees. Also, inclinometers are highly sensitive to linear acceleration and environmentally induced magnetic fields and require 
TABLE 1: Commercial inclinometer.

\begin{tabular}{lccccc}
\hline Device name & Manufacturer & Measuring range (degree) & Accuracy (degree) & Resolution (degree) & Sampling rate (Hz) \\
\hline ACA2200 [16] & RION & \pm 90 & \pm 0.003 & 0.0001 & 20 \\
JN2101 [17] & Ifm electronic & \pm 45 & \pm 0.1 & 0.01 & 20 \\
DNS-85-D2 [18] & MP SENSOR & \pm 85 & \pm 0.01 & 0.001 & 100 \\
BND-HI-INC-MR-PS [19] & Bean Device & \pm 30 & \pm 0.05 & 0.001 & 100 \\
\hline
\end{tabular}

a long response time. Gyro sensors popular in mechanical applications can only measure the angular speed-the rate at which rotation angle changes. Integrating this angular speed with respect to time gives the value for the rotation angle, although the precision obtained from this is less than the required one.

Vision-based systems have been developed to measure rotational angle of large civil structures. Lee et al. utilized multiple camcorders and image processing techniques to measure the dynamic rotational angle of a structure [14]. However, vision-based systems are easily affected by external changes such as weather and illumination and only work properly if installed in the correct line of sight. On top of that, the distance from camera to the target affects the measurement accuracy. Jeon et al. introduced 6-DOF displacement measurement system using a paired structured light system which incorporates lasers, cameras, and screens [15]. The system requires very complex equipment on each side, consisting of one manipulator with two laser pointers, one camera, and one screen. The effectiveness of the system was not fully validated through a full-scale test.

In this study, a new measurement system was developed to provide a practical means for measuring the dynamic rotational angle of a bridge support. It features high resolution and accuracy compared with the available systems on the market. Laboratory experiments were conducted to investigate the system's accuracy and to validate the applicability of the developed system. The effectiveness of the developed system was verified through field tests on real bridges. Rotational angles at supports were measured from truck loading tests and compared with the results from finite element analysis to show the reliability of the measured data.

\section{The Proposed Rotational Angle Measurement System}

The measurement system is composed of a laser source, a frame grabber, and a camcorder. The laser used in this study is a green laser module with a wavelength of $532 \mathrm{~nm}$, divergence of $0.5 \mathrm{mrad}$, and an operating distance of $50 \mathrm{~m}$. The frame grabber has a resolution of $640 * 480$ pixels and a capture speed of 30 frames per second. A commercially available home video camcorder was used.

Figure 1 explains the measurement procedures for the proposed rotational angle measurement system. The rotational angle can be calculated from the displacement data obtained by image processing techniques [14]. The first step is hardware installation. The laser is firmly attached at the bottom of the bridge girder or a bridge deck at support. The target panel is installed at a bridge pier or an abutment on the other side, which is regarded as a fixed location. The target should be installed perpendicularly to the laser beam. The distance between the laser and target can be predetermined. The target size with four white spots can be determined considering the actual size of target area, which can be traced by a camera with a telescopic lens. The second step is calibration. To convert the pixel information to actual displacement, a target image with four spots is captured. The horizontal and vertical lengths $\left(L_{x}, L_{y}\right)$ can be determined considering the maximum displacement of the laser source. A transformation matrix and scaling factors can be calculated by direction vectors and the actual size of the target. The last step is tracing the laser source and calculation of rotational angle. When a moving vehicle runs over the bridge, the support will rotate together with the attached laser pointer. The projected laser on the target can be traced by a camcorder and the displacement can be calculated by scaling factors and a transformation matrix determined in the second step. Finally, the rotational angle of the bridge support can be calculated by the measured displacement divided by the distance from laser source to the target.

\section{Verifications through Laboratory Tests}

3.1. Accuracy of the Proposed System. Firstly, a laboratory test was conducted to investigate the accuracy of the proposed system. The test setup is shown in Figure 2. The laser pointer was placed at $10 \mathrm{~m}, 15 \mathrm{~m}, 20 \mathrm{~m}, 25 \mathrm{~m}$, and $30 \mathrm{~m}$ away from the target, respectively, to check the system's accuracy with respect to the distance between the laser source and the target. The laser images on the target were recorded for 15 minutes. During the test, all devices were mounted on heavy metal jigs and placed on a stable surface to minimize ambient noise effect, and no movement was made to investigate the measurement system's accuracy only.

Figure 3 shows a captured image of the target for calibration. The camera was installed $1 \mathrm{~m}$ away from the target. It has four spots with a size of $10 \mathrm{~mm}$. The image has a resolution of $640 \times 480$ pixels. Considering the top and bottom margins of the target image, the full vertical length is about $20 \mathrm{~mm}$. Thus, the resolution can be calculated as $20 \mathrm{~mm} / 480$ pixels $=$ $0.042 \mathrm{~mm} /$ pixel.

Figure 4 shows the measured data for all cases. Figure 5 and Table 2 summarized the RMS (root-mean-square) noise level in relation to distance. The results showed that as the distance between laser and target increases, the noise level increases in terms of displacement. However, the noise level 


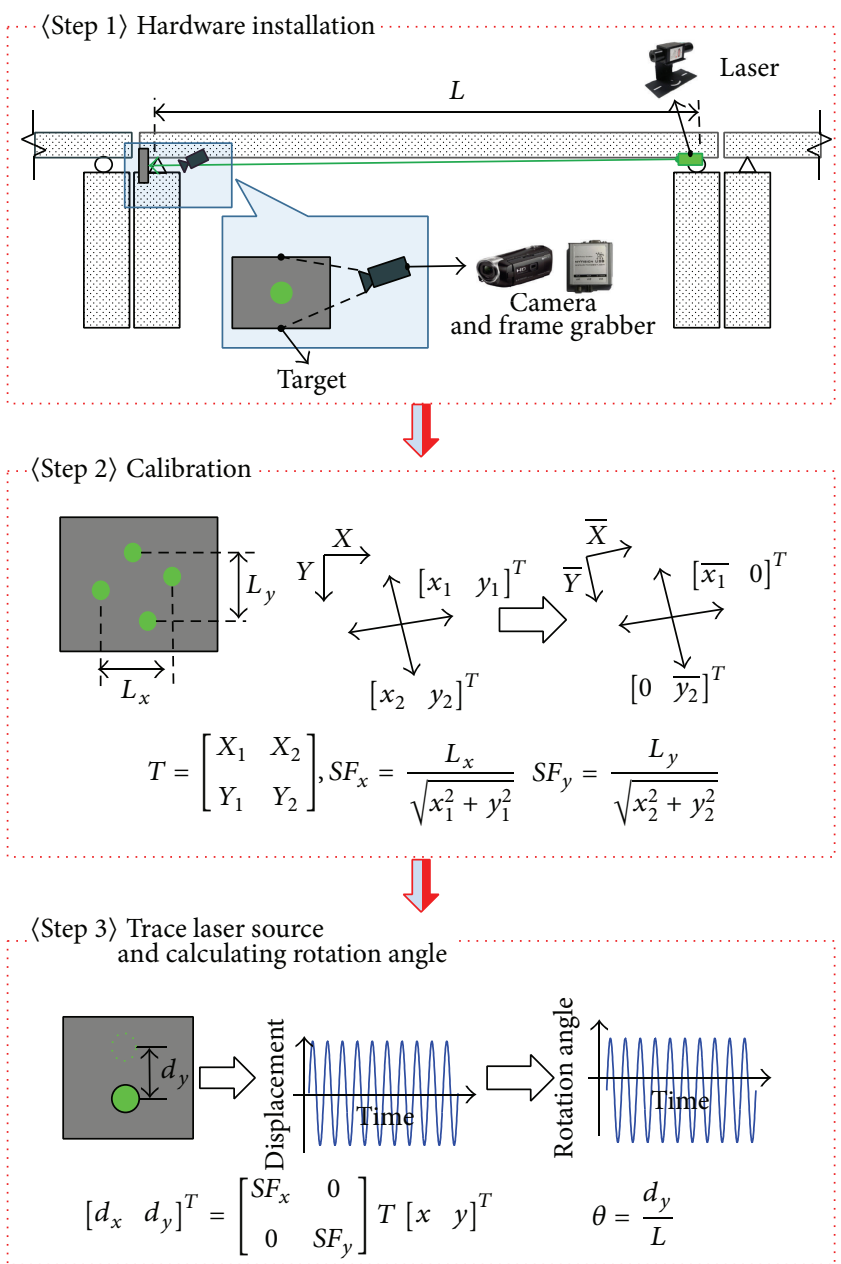

FIGURE 1: Procedures for the proposed rotational angle measurement.

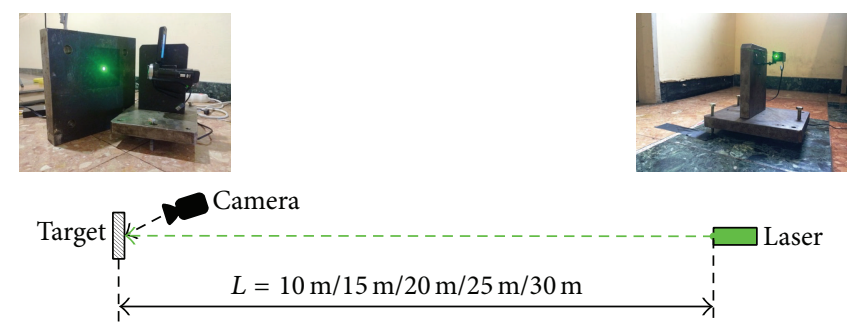

FIGURE 2: Laboratory test setup.

in rotational angle does not proportionally increase to the distance but shows only a slight increase. The noise level for the distance up to $30 \mathrm{~m}$ is found to be around $1.8 \times$ $10^{-4}$ degrees. From the test results, it has been found that the proposed system is very accurate compared with the commercial system.

3.2. Applicability of the Proposed System. Further experiments were carried out on an acrylic model bridge to verify the applicability of the proposed system. The model bridge consists of three girders, nine equally spaced crossbeams, a slab with $10 \mathrm{~mm}$ thickness, and columns connecting bridge girders and supporting steel plates. Detailed dimensions of the model bridge are shown in Figure 6. Numerical analysis was performed using commercial structural analysis software to provide reference values to be compared with. The slab was modeled using shell elements while girders and crossbeams were modeled using frame elements. Figure 7 shows the test setup. Static loads were introduced at the center of the slab from weights of $10 \mathrm{~kg}$ to $25 \mathrm{~kg}$ in $5 \mathrm{~kg}$ increments. The laser 

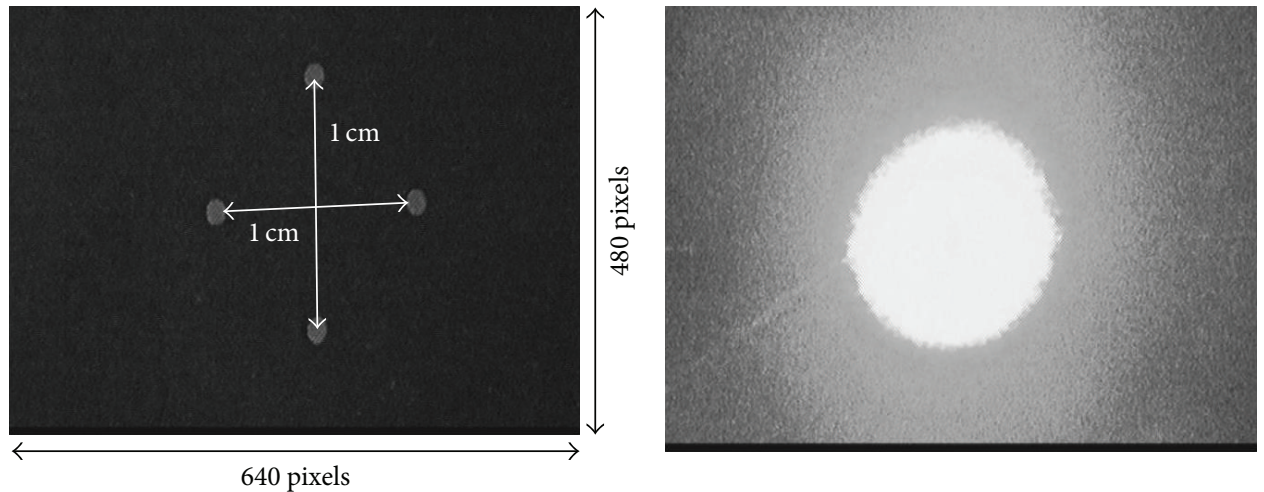

FIGURE 3: Images of calibration target and laser projected on black panel.
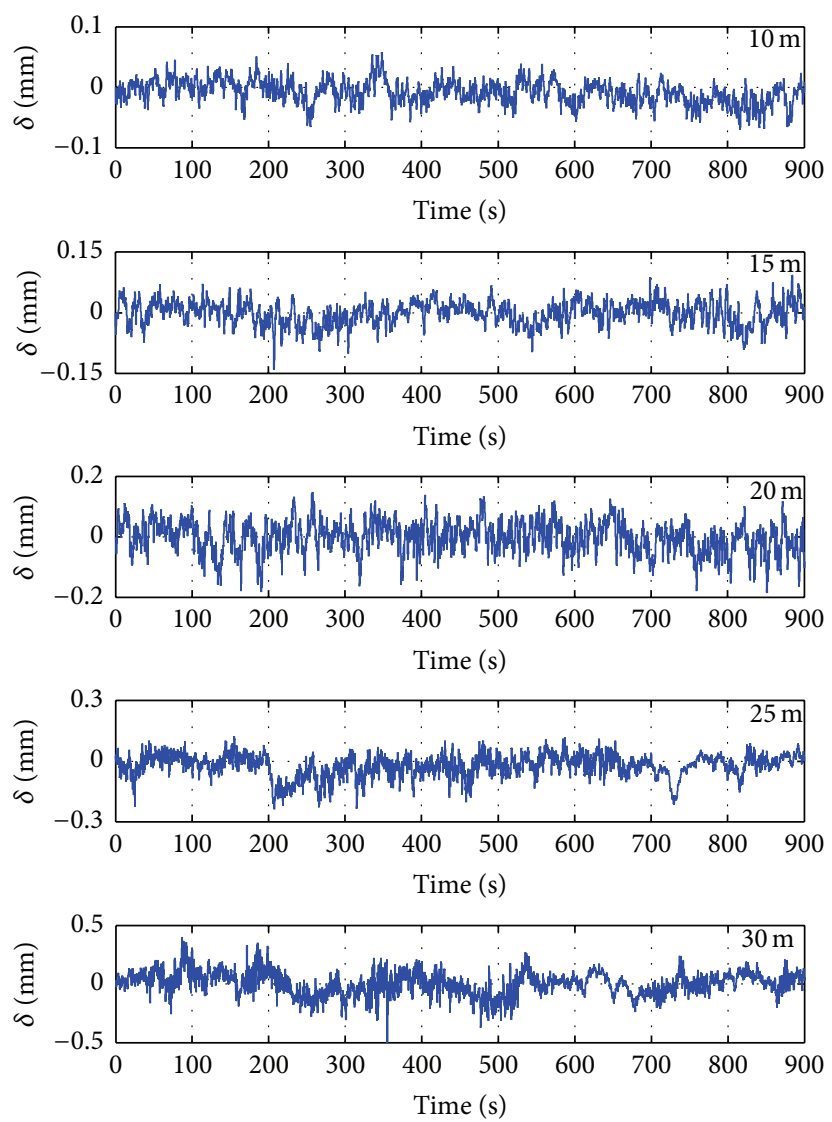

FIGURE 4: Measured data for checking the system's accuracy.

pointer was installed on the slab at support location. The target was positioned at $500 \mathrm{~mm}$ apart from the support, not at the opposite support, to secure line of sight from loading. The displacement at the center of the bridge was also measured for the purpose of comparison.

Table 2 shows the results obtained from both laboratory test and numerical analysis. Both the displacement at the center of bridge and the rotational angle showed a linear increase as the applied loads. The ratios between displacement and rotational angle were found to be consistent with less than $1.5 \%$ difference. The ratio obtained from numerical simulation was $676.3 \mathrm{~mm}$. Results obtained from laboratory tests and numerical analysis closely matched verifying the reliability of the proposed system.

\section{Applications to Real Bridges}

To verify the performance of the proposed system in a real case, a field test was carried out on a single span, prestressed concrete (PSC) bridge as shown in Figure 8(a). 
TABLE 2: Results of a laboratory test.

\begin{tabular}{|c|c|c|c|c|c|c|}
\hline \multirow{2}{*}{ Weight $(\mathrm{Kg})$} & \multicolumn{3}{|c|}{ Test result } & \multicolumn{3}{|c|}{ Numerical simulation } \\
\hline & $\delta(\mathrm{mm})$ & $\theta(\mathrm{rad})$ & $\delta / \theta(\mathrm{mm} / \mathrm{rad})$ & $\delta(\mathrm{mm})$ & $\theta(\mathrm{rad})$ & $\delta / \theta(\mathrm{mm} / \mathrm{rad})$ \\
\hline 10 & 3.195 & 0.00465 & 687.1 & 3.225 & 0.00477 & 676.3 \\
\hline 15 & 4.807 & 0.00710 & 677.0 & 4.838 & 0.00715 & 676.3 \\
\hline 20 & 6.432 & 0.00933 & 689.4 & 6.451 & 0.00954 & 676.3 \\
\hline 25 & 8.052 & 0.01180 & 682.4 & 8.063 & 0.01192 & 676.3 \\
\hline
\end{tabular}
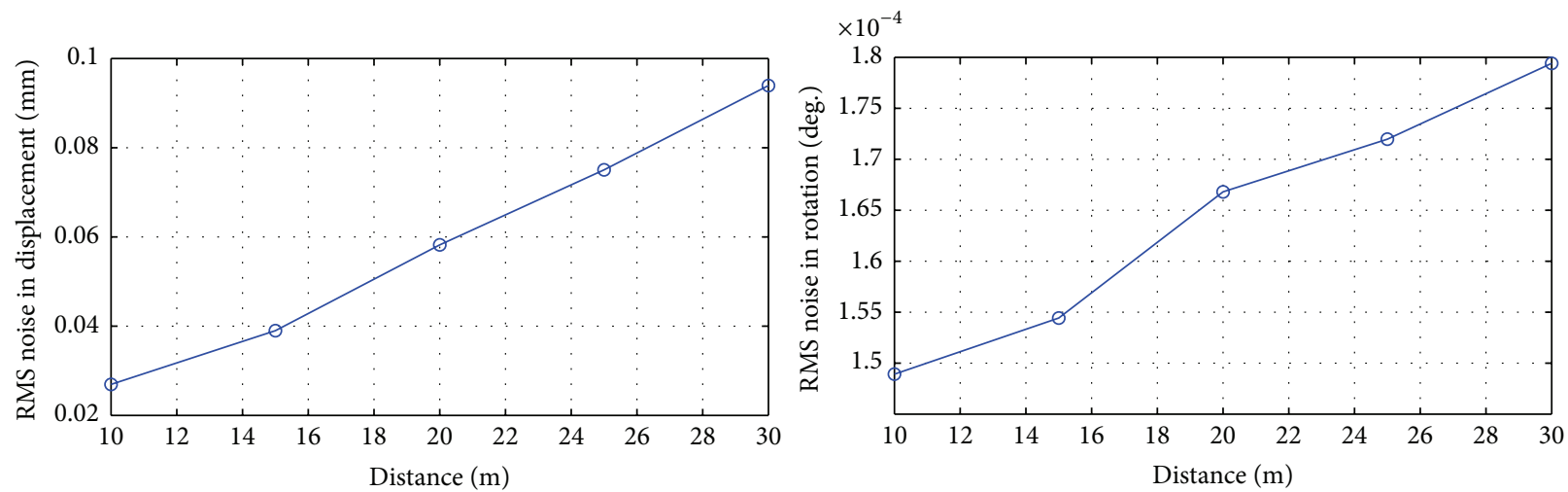

FIGURE 5: RMS noise level.

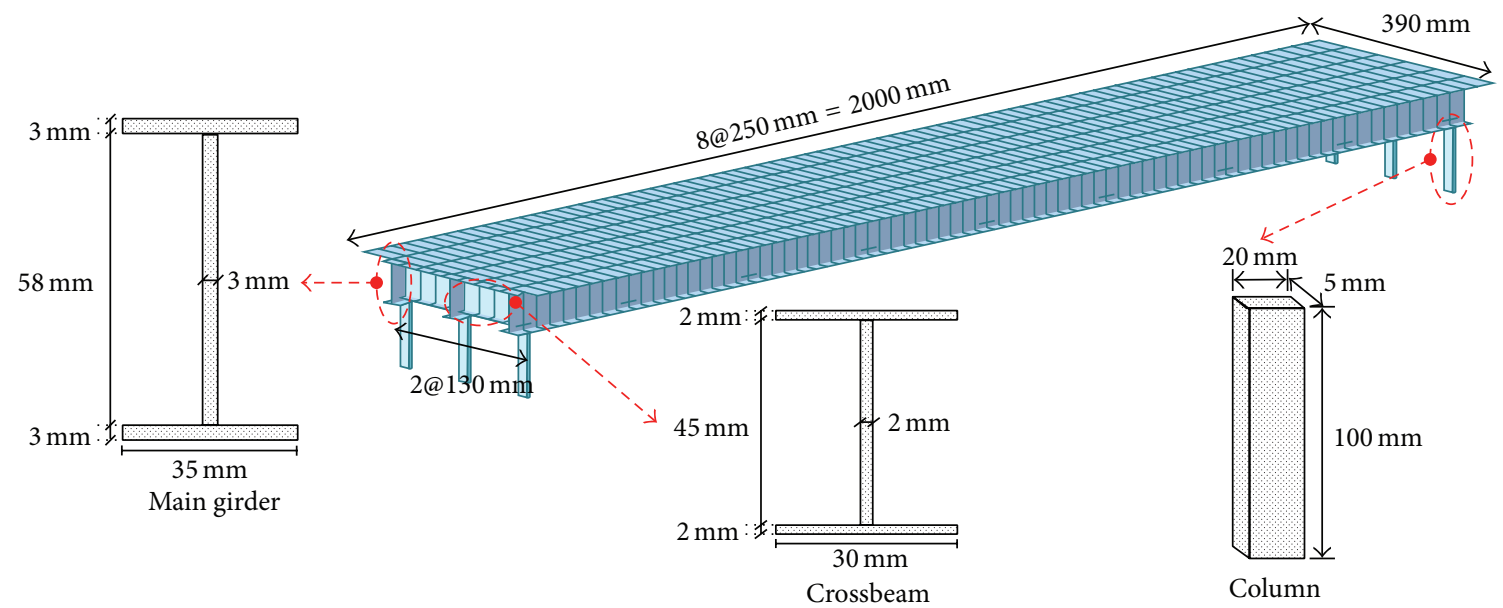

FIGURE 6: Numerical model for comparing laboratory test results.

Vehicle running tests were performed using a dump truck with a weight of 27.1 tons and a running speed of $5 \mathrm{~km} / \mathrm{hr}$. Two test cases were considered. The truck moved forward along the outer traffic lane and backward along the inner traffic lane. The experimental setup on the bridge is shown in Figure 8(b). Two lasers were deployed to trace the rotation of each bridge support. These lasers were attached to the bottom of the girders near the supports along the inner bridge girder. The targets were located at the opposite piers of the bridge. Cameras were installed near the targets. It is notable that it is required to install the measurement system very firmly, since the stability of system components is critical in measuring very small bridge responses.

Figure 9 shows all test results for two loading cases. The rotational angles when moving backward were slightly bigger than the results when moving forward. The measured values showed very consistent results having about $2 \%$ difference. The maximum rotational angle was less than 0.009 degrees, which cannot be measured by commercial hardware. From these results, it can be concluded that the proposed system can measure the dynamic rotational angle of bridge support with high accuracy and reliability. 

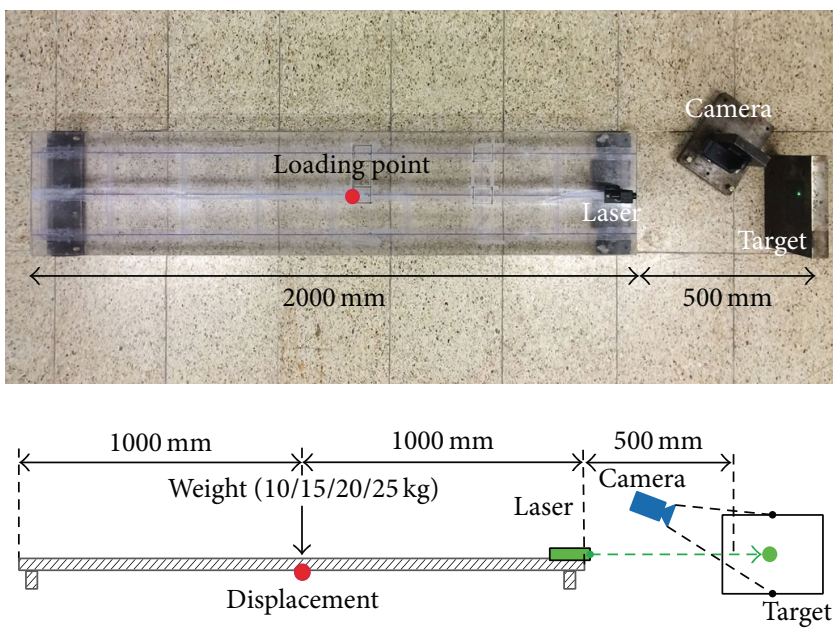

FigURE 7: Laboratory test setup.

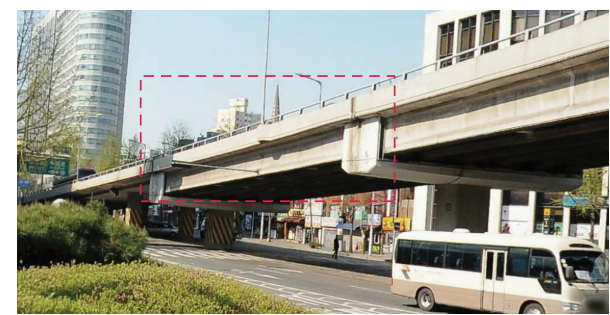

(a) The test bridge

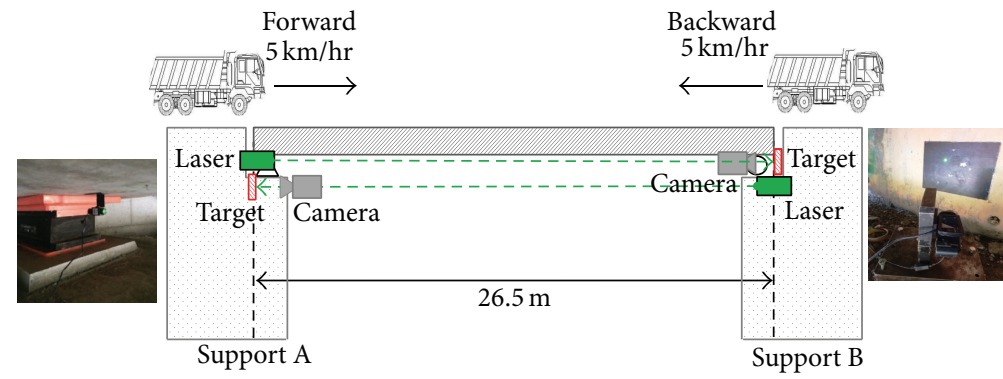

(b) Test setup

FIgURE 8: Field test on a single span PSC girder bridge.

Another field test was carried out on a three-span, PSC girder bridge shown in Figure 10(a). The experimental setup on the bridge is shown in Figure 10(b). Vehicle loading tests were performed using a dump truck with a total weight of 38.8 tons, traveling at random speeds and lanes.

Figure 11 shows four sample results. The rotational angle at support $A$ was bigger than the angle at support $B$, since the test bridge is a continuous bridge. The ratio of two rotational angles $\left(\theta_{\mathrm{B}} / \theta_{\mathrm{A}}\right)$ was numerically calculated. For the analysis, the test bridge was modeled using commercial finite element analysis software. The numerical result for the ratio $\left(\theta_{\mathrm{B}} / \theta_{\mathrm{A}}\right)$ is 0.564 . Measured data showed a close match to the numerical result. Therefore, it can be concluded that the rotational angle of the bridge support can be successfully obtained by the proposed system.

\section{Concluding Remarks}

Measuring the dynamic rotational angle of a bridge support requires a highly accurate measurement device. In this study, we developed a single-point vision-based rotational angle measurement system for bridge support. By the combinational use of a laser pointer and a vision-based displacement measurement system, the measurement accuracy was significantly increased. The accuracy and applicability were investigated through laboratory tests. From the laboratory tests, it has been found that the developed system can be applicable to bridge support with very small rotational angle. From the full-scale implementation on two PSC girder bridges, it is observed that the proposed system can measure the rotational angle with a high accuracy and reliability. In conclusion, the proposed vision-based rotational angle measurement system provides a highly accurate and effective alternative to measure dynamic rotational angle of bridge support.

\section{Conflict of Interests}

The authors declare no conflict of interests.

\section{Authors' Contribution}

Mr. Young-Soo Park is the first author of this paper, which naturally means his contribution is significant in system development, experiments, and writing. Mr. John Arbie Agbayani contributed to this paper partially in experiments and mainly in writing. Dr. Jong-Han Lee also contributed to this paper partially in experiments and writing. Dr. Jong-Jae Lee is the corresponding author and contributed to this paper in all aspects from funding to writing. 

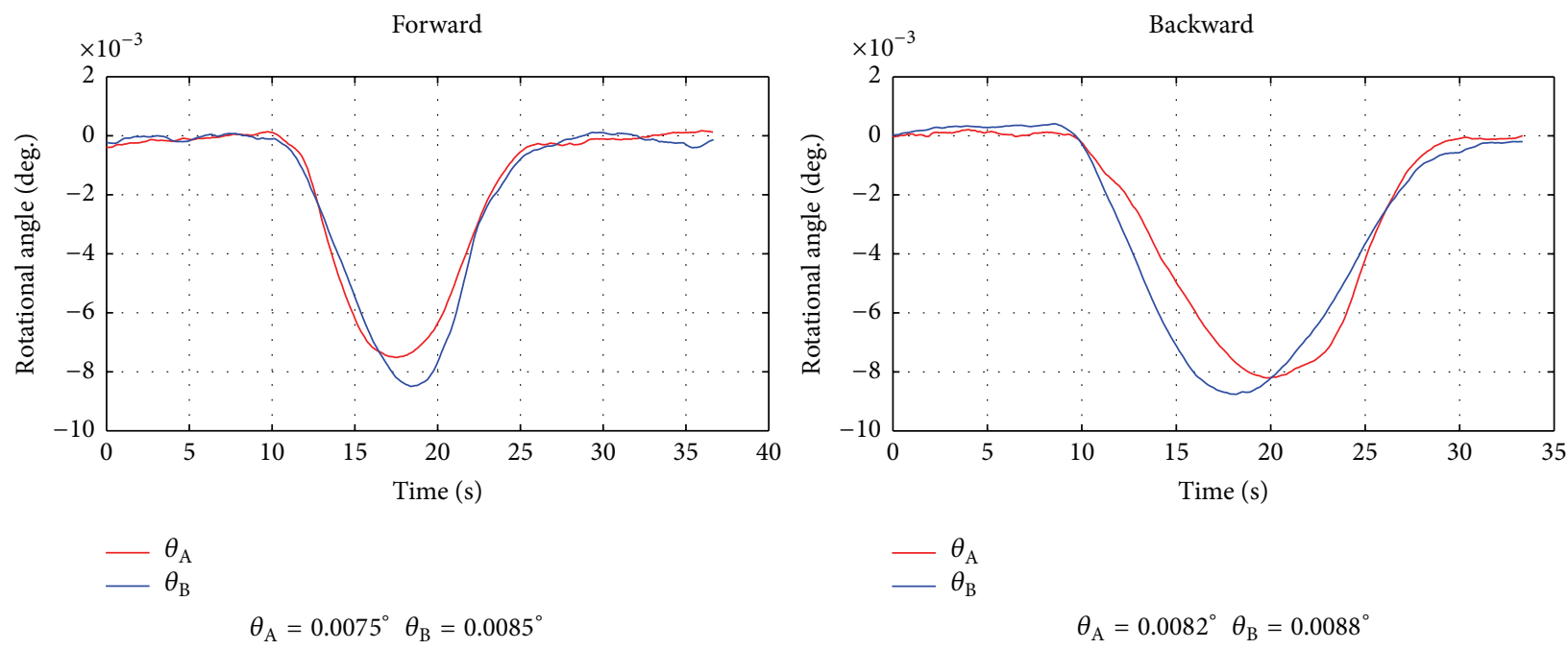

$$
\theta_{\mathrm{A}}=0.0082^{\circ} \theta_{\mathrm{B}}=0.0088^{\circ}
$$
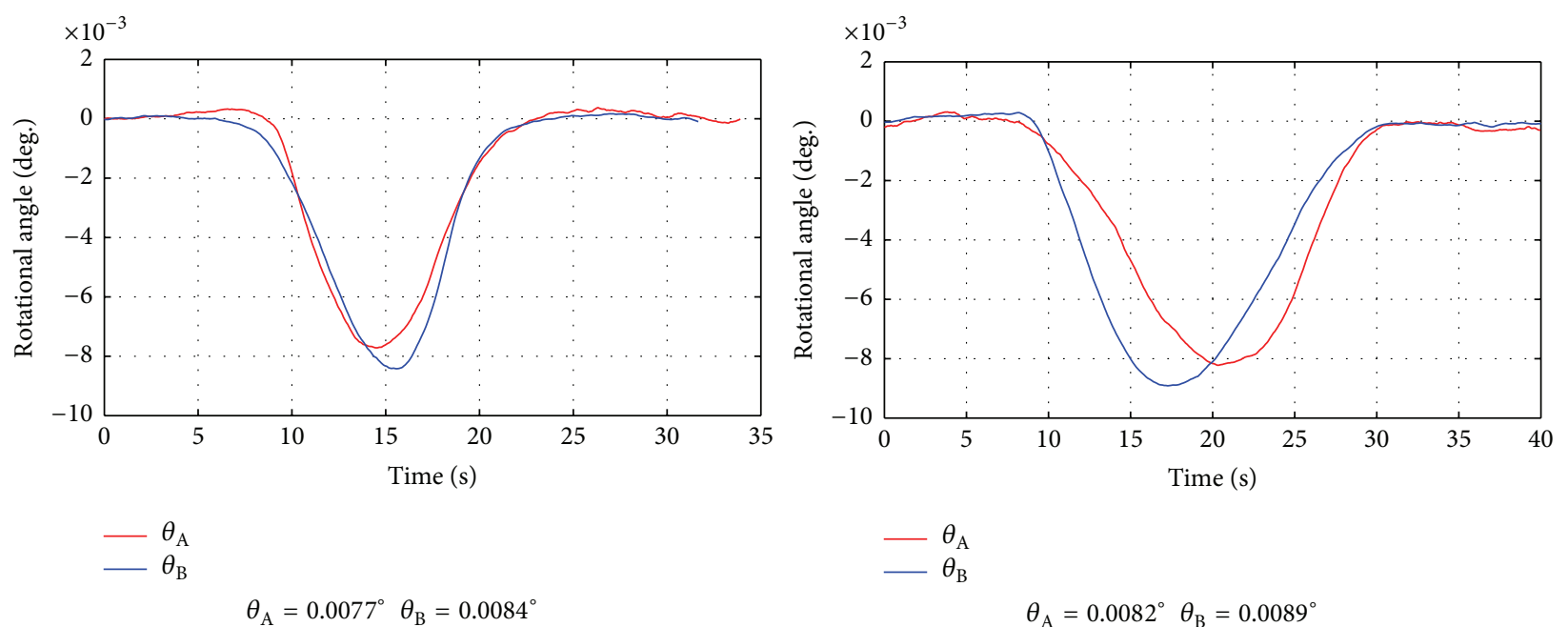

$\theta_{\mathrm{A}}$
$-\theta_{\mathrm{B}}$
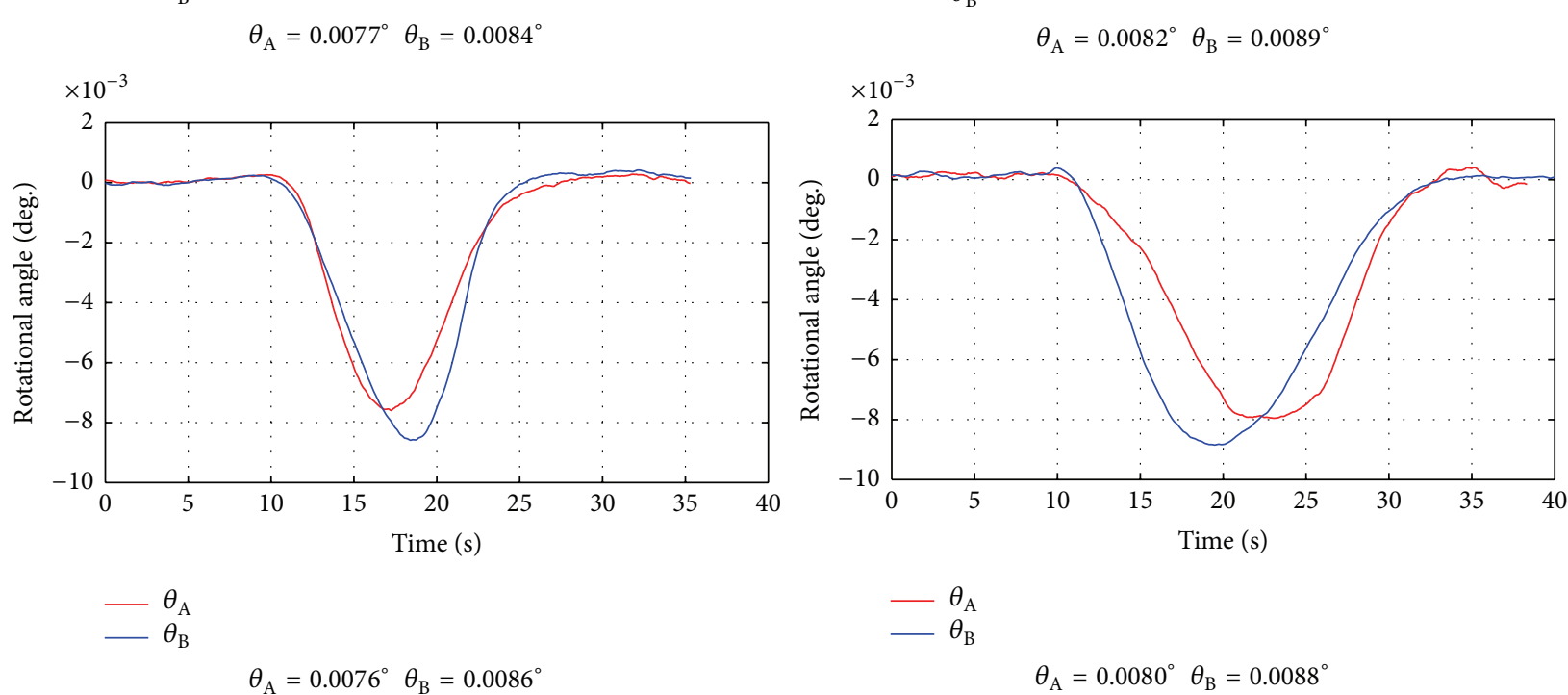

$\begin{aligned} & -\theta_{\mathrm{A}} \\ & -\theta_{\mathrm{B}}\end{aligned} \theta_{\mathrm{A}}=0.0076^{\circ} \quad \theta_{\mathrm{B}}=0.0086^{\circ}$

$\theta_{\mathrm{A}}=0.0080^{\circ} \quad \theta_{\mathrm{B}}=0.0088^{\circ}$

FIGURE 9: Test results on a single span bridge. 

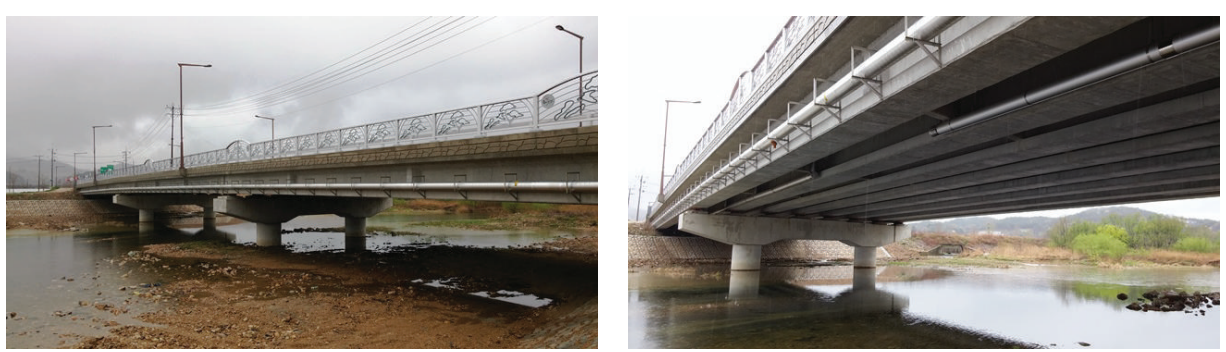

(a) The test bridge

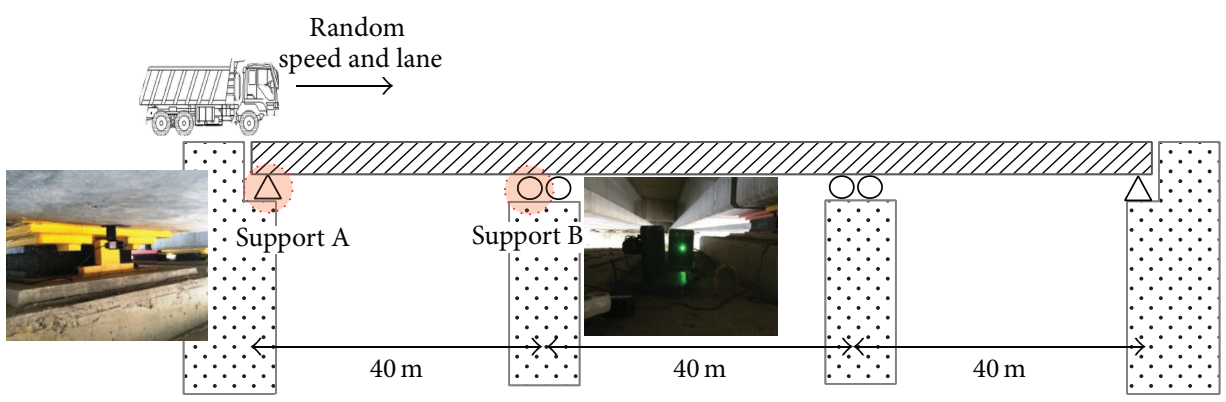

(b) Test setup

FIGURE 10: Field test on a continuous PSC girder bridge.
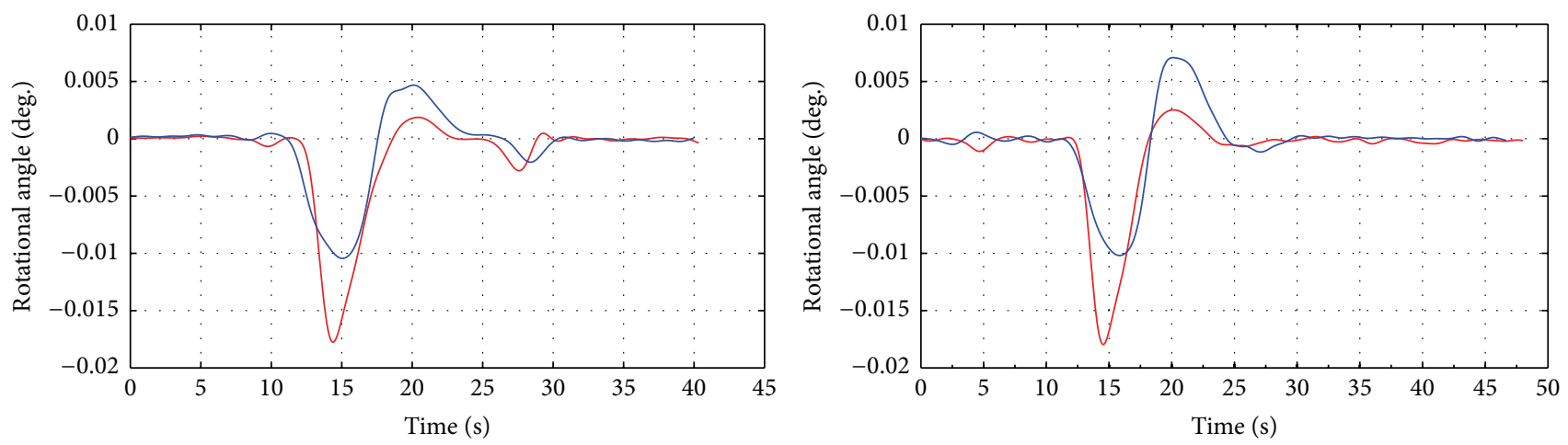

\section{$\theta_{\mathrm{A}}$
$-\theta_{\mathrm{B}}$}

$\theta_{\mathrm{A}}=0.0177^{\circ}, \theta_{\mathrm{B}}=0.0104^{\circ}, \theta_{\mathrm{B}} / \theta_{\mathrm{A}}=0.588$

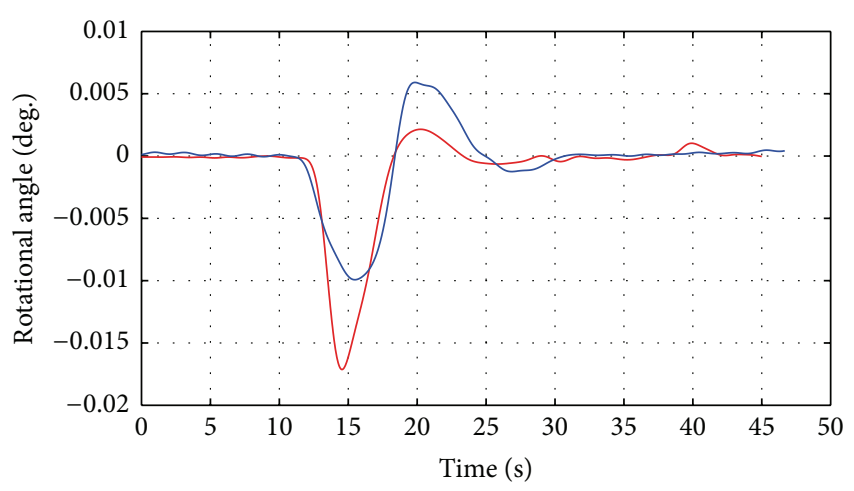

$-\theta_{\mathrm{A}}$
$\theta_{\mathrm{B}}$
$\theta_{\mathrm{A}}=0.0171^{\circ}, \theta_{\mathrm{B}}=0.0099^{\circ}, \theta_{\mathrm{B}} / \theta_{\mathrm{A}}=0.579$
$-\theta_{\mathrm{A}}$

$-\theta_{\mathrm{B}}$

$\theta_{\mathrm{A}}=0.0182^{\circ}, \theta_{\mathrm{B}}=0.0106^{\circ}, \theta_{\mathrm{B}} / \theta_{\mathrm{A}}=0.582$

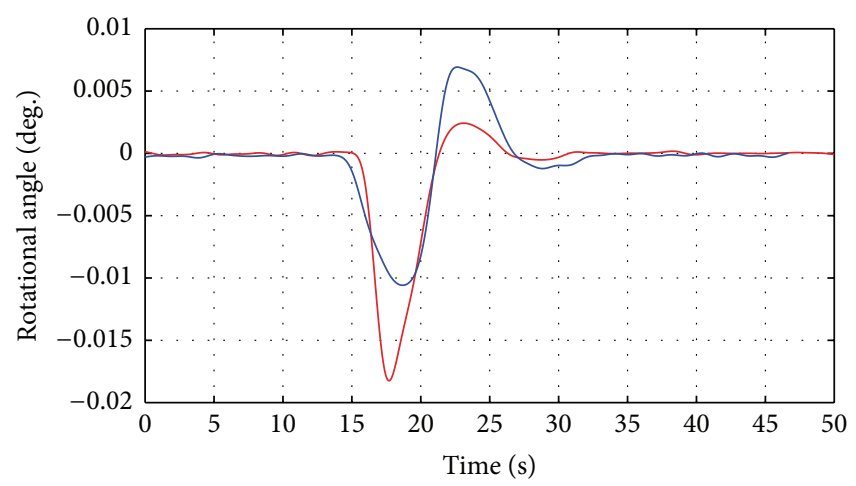

$-\theta_{\mathrm{A}}$
$\theta_{\mathrm{B}}$
$\theta_{\mathrm{A}}=0.0180^{\circ}, \theta_{\mathrm{B}}=0.0102^{\circ}, \theta_{\mathrm{B}} / \theta_{\mathrm{A}}=0.567$

Figure 11: Test results on a continuous bridge. 


\section{Acknowledgments}

This research was supported by a grant (13SCIPA01) from Smart Civil Infrastructure Research Program funded by the Ministry of Land, Infrastructure and Transport (MOLIT) of Korea government and Korea Agency for Infrastructure Technology Advancement (KAIA).

\section{References}

[1] J. M. W. Brownjohn, "Structural health monitoring of civil infrastructure," Philosophical Transactions of the Royal Society A: Mathematical, Physical and Engineering Sciences, vol. 365, no. 1851, pp. 589-622, 2007.

[2] J. J. Lee and M. Shinozuka, "A vision-based system for remote sensing of bridge displacement," NDT \& E International, vol. 39, no. 5, pp. 425-431, 2006.

[3] X. Hou, X. Yang, and Q. Huang, "Using inclinometers to measure bridge deflection," Journal of Bridge Engineering, vol. 10, no. 5, pp. 564-569, 2005.

[4] C. Gentile, "Deflection measurement on vibrating stay cables by non-contact microwave interferometer," NDT and E International, vol. 43, no. 3, pp. 231-240, 2010.

[5] A. P. Adewuyi, Z. Wu, and N. H. M. Kammrujaman Serker, "Assessment of vibration-based damage identification methods using displacement and distributed strain measurements," Structural Health Monitoring, vol. 8, no. 6, pp. 443-461, 2009.

[6] J.-W. Park, S.-H. Sim, and H.-J. Jung, "Displacement estimation using multimetric data fusion," IEEE/ASME Transactions on Mechatronics, vol. 18, no. 6, pp. 1675-1682, 2013.

[7] S. Cho, J. Park, H. Jung et al., "Structural health monitoring of a cable-stayed bridge using acceleration data via wireless smart sensor network," Smart Structures and Systems, vol. 6, p. 87786, 2010.

[8] H. H. Nassif, M. Gindy, and J. Davis, "Comparison of laser Doppler vibrometer with contact sensors for monitoring bridge deflection and vibration," NDT and E International, vol. 38, no. 3, pp. 213-218, 2005.

[9] L. Deng and C. S. Cai, "Applications of fiber optic sensors in civil engineering," Structural Engineering and Mechanics, vol. 25, no. 5, pp. 577-596, 2007.

[10] B. F. Spencer, H. Jo, K. A. Mechitov et al., "Recent advances in wireless smart sensors for multi-scale monitoring and control of civil infrastructure," Journal of Civil Structural Health Monitoring, 2015.

[11] T. W. Ryan, J. E. Mann, Z. M. Chill, and B. T. Ott, Bridge Inspector's Reference Manual (BIRM), 2012.

[12] M. Aria and R. Akbari, "Inspection, condition evaluation and replacement of elastomeric bearings in road bridges," Structure and Infrastructure Engineering, vol. 9, no. 9, pp. 918-934, 2013.

[13] J. C. Park, C. M. Park, and P. Y. Song, "Evaluation of structural behaviors using full scale measurements on the Seo Hae CableStayed Bridge," Journal of the Korean Society of Civil Engineers, vol. 24, no. 2, pp. 249-257, 2004.

[14] J.-J. Lee, H.-N. Ho, and J.-H. Lee, "A vision-based dynamic rotational angle measurement system for large civil structures," Sensors, vol. 12, no. 6, pp. 7326-7336, 2012.

[15] H. Jeon, Y. Bang, and H. Myung, "A paired visual servoing system for 6-DOF displacement measurement of structures," Smart Materials and Structures, vol. 20, no. 4, Article ID 045019, 2011.
[16] Shenzhen RION Technology, http://en.rion-tech.net/products _detail/\&productId=111.html.

[17] ifm electronic gmbh, http://www.ifm.com/products/gb/ds/ JN2100.htm.

[18] MP-SENSOR GmbH, http://www.mp-sensor.de/en/products/ elektronische-neigungsschalter.html.

[19] Rethinking Sensing Technology, http://www.beanair.com/products/beandevice/beandevice-smart-sensor-hiinc-xrange. 


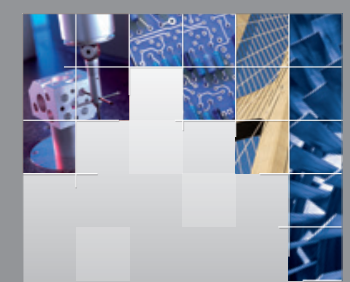

\section{Enfincering}
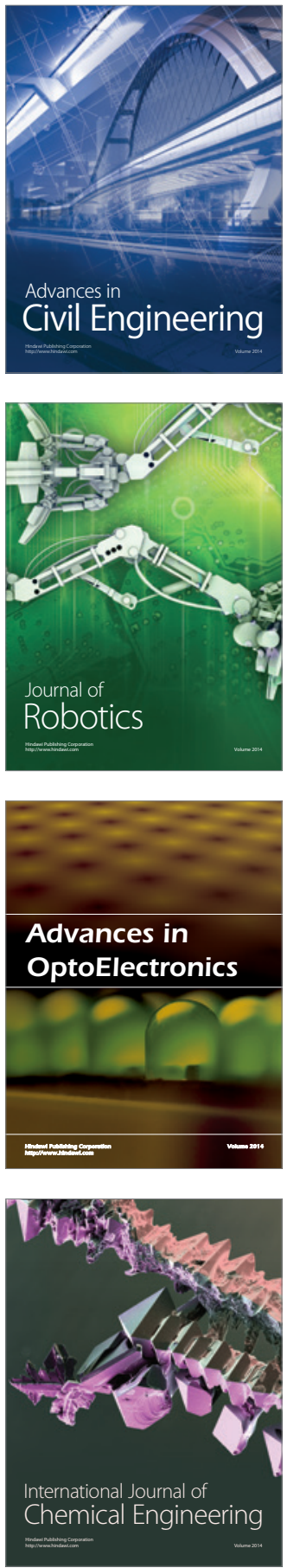

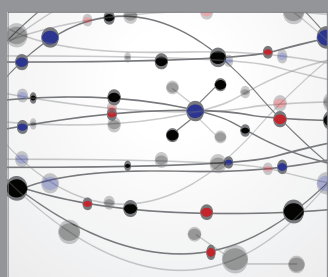

The Scientific World Journal

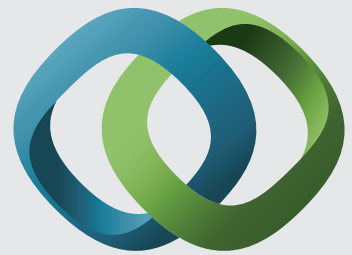

\section{Hindawi}

Submit your manuscripts at

http://www.hindawi.com
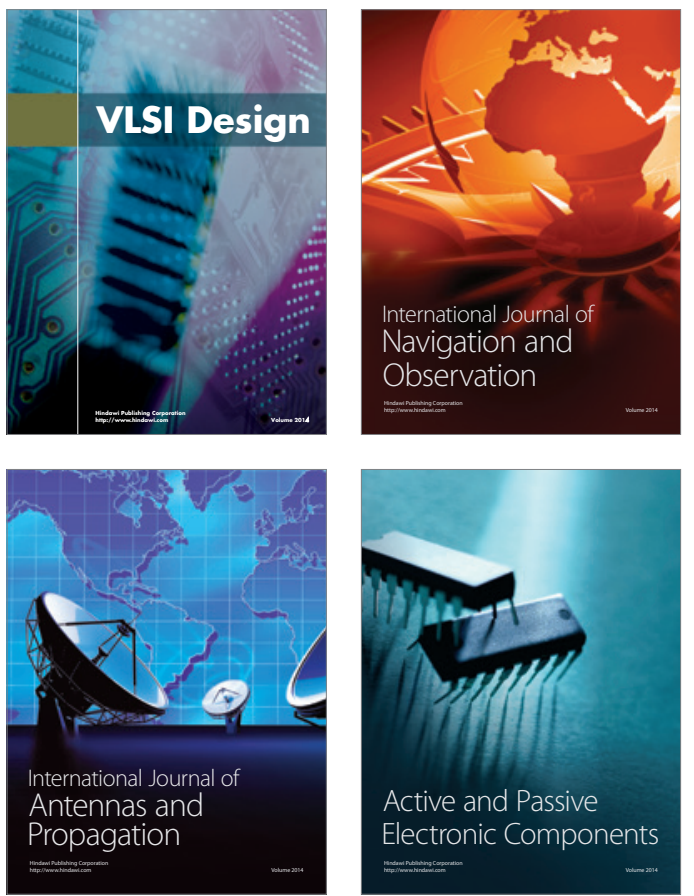
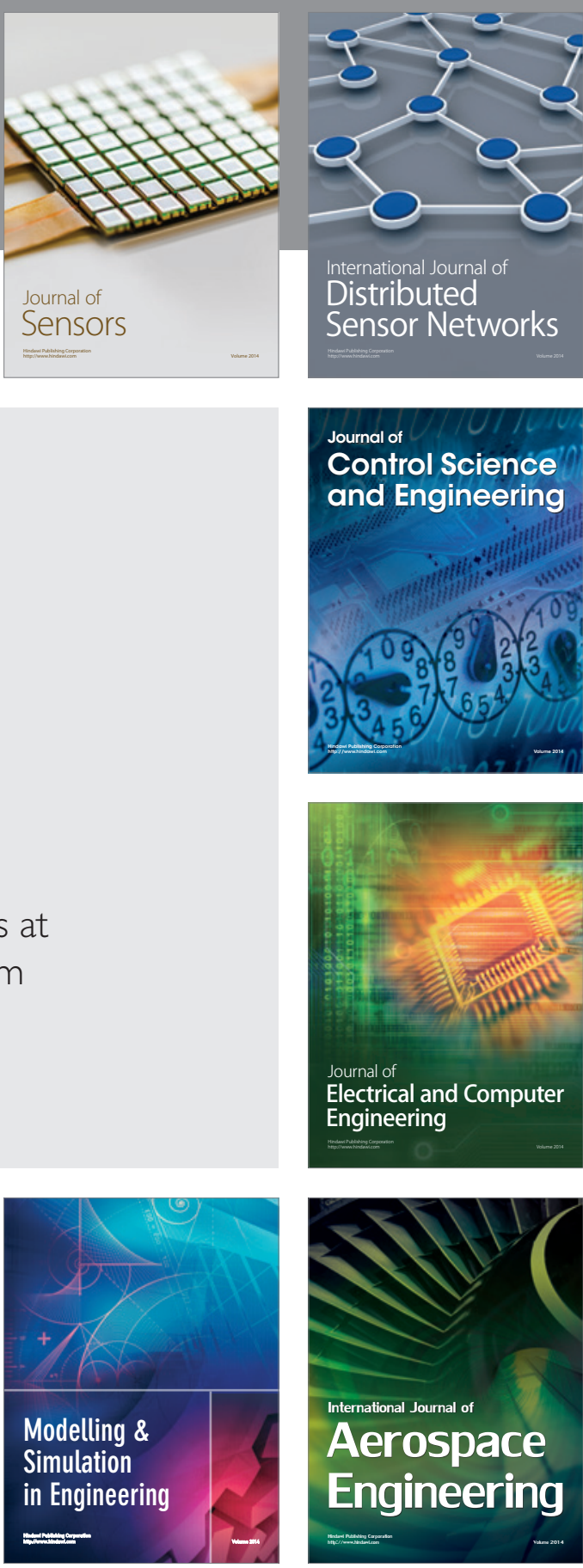

International Journal of

Distributed

Sensor Networks

Journal of

Control Science

and Engineering
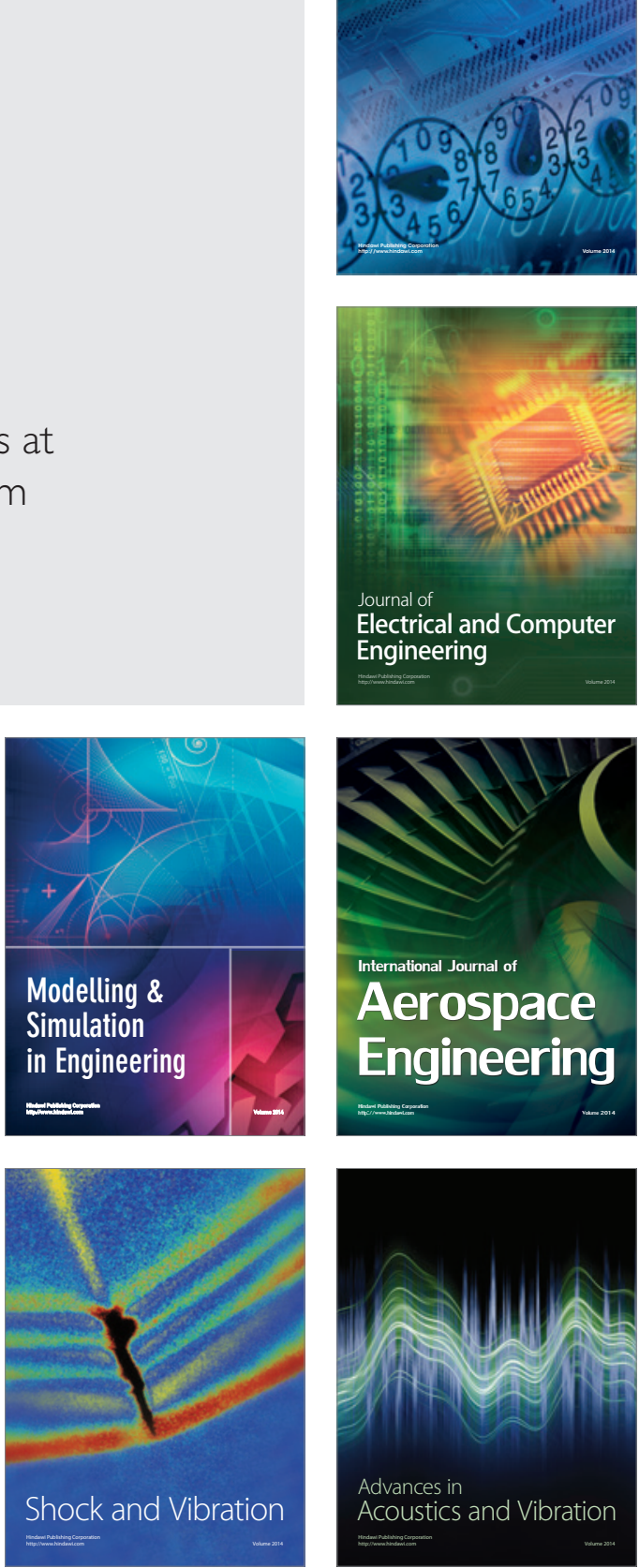